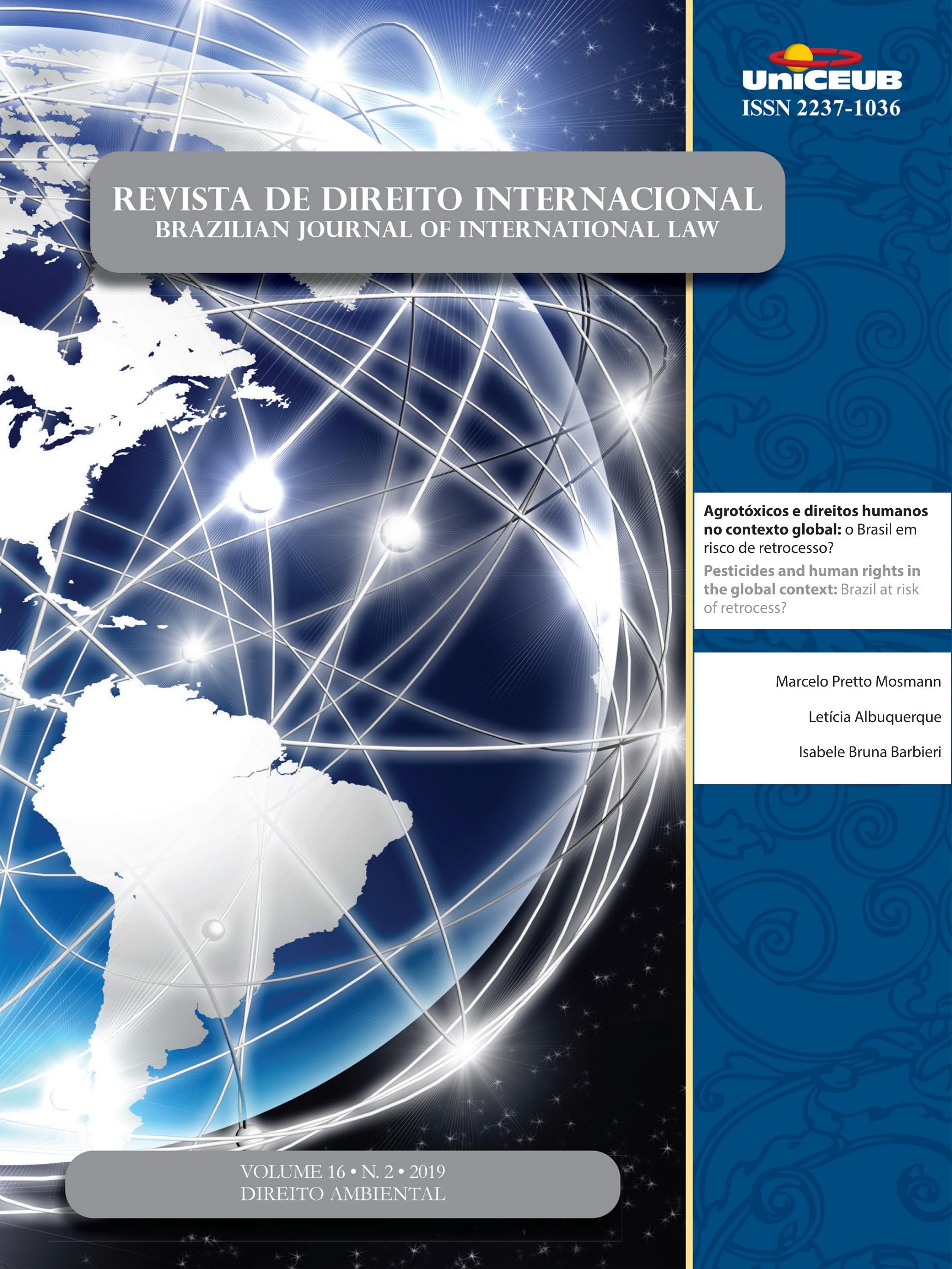




\section{Sumário}

I. Crônicas do Direito Internacional .................................................1

AMAZONIE: LE DROIT INTERNATIONAL EN VIGUEUR APPORTE DES RÉPONSES SUBSTANTIELLES ... 3 Pierre-Marie Dupuy

A eVOluÇão da SOluÇão DE CONTROVÉRSias NOS ACFIs 8 Ana Rachel Freitas da Silva

II. Dossiê Especial: Direito ambientai 14

A brief overview of Sustainable DeVelopment: HOW A DEBATEd CONCEPT With A MUCH-CONTESTED LEGAL NATURE COULD PERFORM A VALUABLE ROLE IN THE DECISION-MAKING ......16 Natali Francine Cinelli Moreira

A meta 11 de Aichi e as Áreas marinhas protegidas em grande ESCALA: proteção ambienTAL OU OPORTUNISMO POLÍTICO?

Alexandre Pereira da Silva

LITIGÂNCIA CLIMÁTICA COMO ESTRATÉGIA JURISDICIONAL AO AQUECIMENTO GLOBAL ANTROPOGÊNICO E MUDANÇAS CLIMÁTICAS

Délton Winter de Carvalho e Kelly de Souza Barbosa

AsSESSMENT AND CHALlENGES OF CARBON MARKETS

Louise Pigeolet e Arnaud Van Waeyenberge

As abordagens dos países da América Latina e Caribe sobre a mobilidade humana proVOCADA PELAS MUDANÇAS CLIMÁTICAS

Diogo Andreola Serraglio e Heline Sivini Ferreira

Implementation of Legal mechanisms of environmental protection by the South PaCIFIC REGIONAL ORGANIZATIONS 116 Joanna Siekiera 
CONCILIATING THE OVERLAP OF PROTECTED AREAS AND TRADITIONAL TERRITORIES: LEGAL INNOVATIONS FOR BIOLOGICAL DIVERSITY CONSERVATION IN BRAZILIAN PARKS

Nathalia Fernandes Lima e Solange Teles Silva

O USO DE DRONES COMO INSTRUMENTO PARA A CONSERVAÇÃo DA BIODIVERSIDADE NO BRASIL141 Larissa Suassuna Carvalho Barros e Marcia Dieguez Leuzinger

Agrotóxicos e direitos humanos no contexto global: o Brasil EM Risco de Retrocesso?

Marcelo Pretto Mosmann, Letícia Albuquerque e Isabele Bruna Barbieri

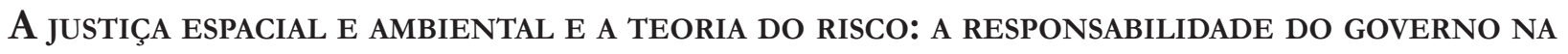
PREVENÇÃo CONTRA DESASTRES (NO BRASIL). 169

José Adércio Leite Sampaio e Edson Rodrigues de Oliveira

The judgment of the case Xucuru People v. Brazil: Inter-American Court of Human RigHTS BETWEEN CONSOLIDATION AND SETBACKS

Gabriela Cristina Braga Navarro

II. Artigos sobre outros temas

NACIONALIDADE: NOVAS REGRAS, VELHOS PROBLEMAS

226

Paulo Henrique Faria Nunes

O EXERCíCIO DA JURISDIÇÃO INTERAMERICANA DE DIREITOS HUMANOS: LEGITIMIDADE, PROBLEMAS E POSSÍVEIS SOLUÇÕES

Felipe Grizotto Ferreira, Guilherme Perez Cabrale Lucas Catib de Laurentiis

A proteção da identidade de gênero na jurisprudênCia da Corte Europeia de Direitos Humanos

Gabriel Coutinho Galil

O COMITÊ JURÍdico INTERAMERICANO dA OEA E A CODIFICAÇÃo DO DIREITO INTERNACIONAL REGIONAL. 
O caso Petruhhin e o princípio do nível mais elevado de proteção no tocante aos diREITOS FUNDAMENTAIS NO ÂMBITO DA UNIÃo EUROPEIA............................................304

Clovis Demarchi e Jaine Cristina Suzin

A AUTONOMia da VONTADE NA ESCOLHA dA LEI APLICÁVEl AOS CONTRATOS DE COMÉRCiO INTER-

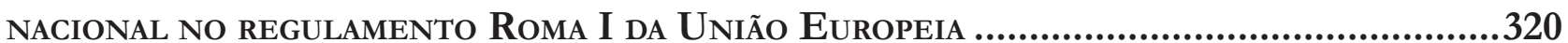

Aline Beltrame de Moura e Rafaela Hörmann

A JuRisdição da ICANN: desafios atuais e Prospectivas futuras...............................335 Aziz Tuffi Saliba e Amael Notini Moreira Bahia

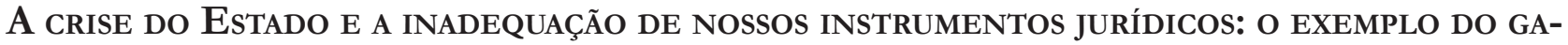
RANTISMO PENAL NO BRASIL.

Oswaldo Poll Costa e Francisco Quintanilha Veras Neto

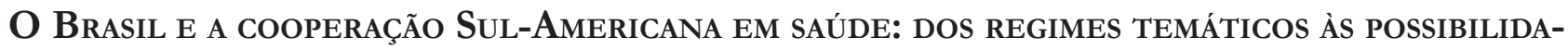
DES DE EFETIVAÇÃo ESTRUTURANTE

Ademar Pozzatti Junior e Luiza Witzel Farias

III. RESENHAS

Resenha da obra: SILVA, Waldimeiry Correa da. Regime internacional de enfrentaMENTO AO TRÁFICO DE PESSOAS: AVANÇOS E DESAFIOS PARA A PROTEÇÃo DOS DIREITOS HUMANOS. Rio de Janeiro: Lumen Juris, 2018. 385

Mércia Cardoso de Souza e Guirino Nhatave 


\title{
Agrotóxicos e direitos humanos no contexto global: o Brasil em risco de retrocesso?*
}

\author{
Pesticides and human rights in the global \\ context: Brazil at risk of retrocess?
}

\author{
Marcelo Pretto Mosmann** \\ Letícia Albuquerque*** \\ Isabele Bruna Barbieri****
}

\section{Resumo}

O objetivo deste artigo é analisar a relação entre Direitos Humanos e meio ambiente a partir da problemática da regulação e uso de agrotóxicos, em especial no Brasil, usando como referência o relatório elaborado pelo relator especial do direito à alimentação juntamente ao Conselho de Direitos Humanos da Organização das Nações Unidas, publicado em 2017. Primeiro realiza-se uma contextualização da atuação do Brasil nas Conferências Mundiais de Meio Ambiente juntamente ao sistema das Nações Unidas e evidenciada a relação com a segurança química. Com base nessa primeira análise, é possível afirmar que há uma adequação das políticas e legislação brasileiras para assegurar uma maior proteção ambiental em matéria de regulação e uso de agrotóxicos. Num segundo momento, apresenta-se a relação, cada vez mais evidente, entre meio ambiente e direitos humanos no contexto do sistema das Nações Unidas, a partir da atuação do Conselho de Direitos Humanos com relação aos agrotóxicos e os riscos de contaminação. Por fim, demonstra-se o atual contexto brasileiro que permite concluir que há um risco de retrocesso ambiental, considerando a liberalização do uso de substâncias proibidas ou mesmo banidas em outros países, justamente pelo risco que representam à saúde humana e ao meio ambiente. Nesse contexto, os instrumentos internacionais de proteção à saúde e ao meio ambiente poderiam ser utilizados para pressionar contra as medidas de flexibilização adotadas pelo governo brasileiro. A metodologia utilizada é a dedutiva com base na consulta à bibliografia especializada, legislações e análise documental.

Palavras-Chave: Direito Internacional. Segurança Química. Retrocesso Ambiental. Agrotóxicos. Ecocídio consentido.

em Direito da Universidade Federal de Santa Catarina (UFSC), líder do Observatório de Justiça Ecológica, Grupo de Pesquisa registrado no CNPq, e coordenadora do Projeto de Extensão Clínica de Justiça Ecológica. E-mail : laetitia.ufsc@gmail.com.

**** Doutoranda em Direito pela Universidade Federal de Santa Catarina. Integrante do Observatório de Justiça Ecológica, Grupo de Pesquisa registrado no $\mathrm{CNPq}$, membro do Projeto de Extensão Clínica de Justiça Ecológica. E-mail : isabele@ibbadvocacia.adv.br.

** Mestrando em Direito pela Universidade do Observatório de Justiça Ecológica, Grupo de Pesquisa que integra o $\mathrm{CNPq}$, membro do Projeto de Extensão Clínica de Justiça Ecológica. E-mail :mosmann@hotmail.com. 
with the United Nations system is presented, and its relationship with chemical safety is highlighted. Based on this first analysis, it is possible to state that there is an adaptation of Brazilian policies and legislation to ensure greater environmental protection in the regulation and use of pesticides. Secondly, the increasingly evident relationship between the environment and human rights is presented in the context of the United Nations system, based on the work of the Human Rights Council in relation to pesticides and the risks of contamination. Finally, the current Brazilian context demonstrates that there is a risk of environmental regression, considering the liberalization of the use of banned substances in other countries, due to the risk they pose to human health and the environment. In this context, the international instruments for protection of health and the environment could be used to press against the flexibilization measures adopted by the Brazilian government. The methodology used is deductive based on consulting the specialized bibliography, legislation and document analysis.

Keywords: International Law. Chemical Safety. Principle of Prohibition of Retrocession. Pesticides. Ecocide consented.

\section{Introdução}

Quando Rachel Carson publicou, em 1962, o livro Primavera Silenciosa, em que denunciava os perigos da indústria química e o uso descontrolado de "veneno" em razão da Revolução Verde, bem como os efeitos danosos para a saúde humana e o meio ambiente, foi considerada uma alarmista. Carson alertava que, pela primeira vez na história do mundo, todo o ser humano está agora sujeito ao contato com químicos perigosos, desde o momento da sua concepção até o momento da sua morte:

em menos de duas décadas de seu uso, os pesticidas sintéticos foram tão amplamente distribuídos pelo mundo animado e inanimado que ocorrem em todos os lugares. Eles foram recuperados da maioria dos principais sistemas fluviais e até mesmo de correntes de águas subterrâneas. Resíduos desses produtos químicos permanecem no solo, nos quais foram aplicados uma dúzia de anos antes ${ }^{1}$.

\footnotetext{
In the less than two decades of their use, the synthetic pesticides have been so thoroughly distributed throughout the animate and inanimate world that they occur virtually everywhere. They have
}

Cinco décadas após a publicação, os relatórios da Organização Mundial da Saúde (OMS) e outras agências especializadas das Nações Unidas apontam para os perigos do uso indiscriminado de agrotóxicos. Segundo o representante da OMS no Brasil, Joaquin Molina, cerca de 193 mil pessoas perdem a vida todos os anos por exposição a substâncias químicas nocivas ${ }^{2}$.

Em 2017, o Conselho de Direitos Humanos das Nações Unidas apresentou ao público o relatório especial sobre a relação entre o uso intensivo de agrotóxicos e seus efeitos nefastos ao direito à alimentação, bem como ao meio ambiente em escala global.

Assim, o objetivo deste artigo é analisar a relação entre Direitos Humanos e meio ambiente com base na problemática da regulação e uso de agrotóxicos, em especial no Brasil, usando como referência o relatório citado.

$\mathrm{Na}$ primeira parte do artigo, será apresentada uma contextualização da atuação do Brasil juntamente ao sistema das Nações Unidas e as conferências mundiais de meio ambiente, em especial com relação a segurança química. Na segunda parte, é demonstrada a relação entre meio ambiente e direitos humanos no contexto da regulação e uso de agrotóxicos, usando como documento para análise o relatório especial do Conselho de Direitos Humanos sobre o direito à alimentação e os efeitos dos agrotóxicos. Na terceira parte, é relatado o cenário atual brasileiro, que, diante a adoção de políticas de liberalização indiscriminada de fabricação, uso e comercialização de agrotóxicos, permite concluir que há um risco de retrocesso ambiental.

A metodologia adotada é a analítica indutiva, realizada a partir da consulta à bibliografia especializada aos temas de Direitos Humanos, Direito Internacional Ambiental e agrotóxicos, bem como a análise documental, em especial o relatório especial sobre o direito à ali-

been recovered from most of the major river systems and even from streams of groundwater flowing unseen through the earth. Residues of these chemicals linger in soil to witch they may have been applied a dozen years before. CARSON, Rachel. Silent Spring. Boston: Mariner Books, 2002. p.15

2 ORGANIZAÇÃO PAN-AMERICANA DA SAÚDE; ORGANIZAÇÃO MUNDIAL DA SAÚDE. OPAS/OMS destaca importância da atuação conjunta de setores da saúde, agricultura e meio ambiente na regulamentação de agrotóxicos. 2018. Disponível em: https://www. paho.org $/$ bra $/$ index.php?option $=$ com_content\&view $=$ article\&i $\mathrm{d}=5756$ :opas-oms-destaca-importancia-da-atuacao-conjunta-dossetores-da-saude-agricultura-e-meio-ambiente-na-regulamentacaode-agrotoxicos\&Itemid=839. Acesso em: 21 jun. 2019. 
mentação e os efeitos dos agrotóxicos do Conselho de Direitos Humanos da ONU.

\section{A segurança química no sistema das Nações Unidas}

O Brasil possui um longo histórico de participação nas conferências mundiais de meio ambiente capitaneadas pela Organização das Nações Unidas (ONU). De 1972, quando foi realizada a Conferência das Nações Unidas sobre Meio Ambiente e Desenvolvimento Humano, em Estocolmo, à 2012, no Rio de Janeiro, por ocasião da Rio +20 , o país construiu um verdadeiro soft power $^{3}$ em matéria de liderança ambiental no cenário internacional.

A Conferência das Nações Unidas sobre Meio Ambiente e Desenvolvimento Humano, de 1972, é considerada um marco na temática ambiental e do desenvolvimento. Para Le Prestre a Conferência marcou uma importante etapa da ecopolítica contemporânea, pois:

\footnotetext{
se uma evolução notável teve lugar depois, o fato é que numerosas questões presentes e debatidas em 1972 continuaram a influenciar as relações entre os atores internacionais no domínio ecológico, e as tendências que se desenharam então não fizeram senão se afirmar em seguida ${ }^{4}$.
}

Durante a Conferência, o debate foi pautado pelas diferentes percepções entre os países desenvolvidos e subdesenvolvidos, reforçando a chamada dicotomia Norte/Sul. Os países do Sul defendiam a posição segundo a qual a maior poluição era a miséria, recusando-se a reconhecer o problema da "explosão demográfica" como causa de danos ambientais, conforme sustentavam os países do Norte. O Brasil exerceu um papel de

\footnotetext{
O conceito de soft power pode ser entendido por um poder brando em contraposição ao chamado hard power, poder duro. Joseph Nye, um dos autores do conceito, salienta que na política mundial, é possível que um país obtenha os resultados que quer porque os outros desejam acompanha-lo, admirando os seus valores, imitando-lhe o exemplo, aspirando ao seu nível de prosperidade e liberdade. Nesse sentido é igualmente tão importante estabelecer a agenda na política mundial e atrair os outros quanto força-los a mudar mediante a ameaça ou o uso das armas militares ou econômicas. É justamente esse aspecto do poder de levar os outros a querer o que você quer, que Nye chama de poder brando, soft power. Nesse sentido ver: NYE, Joseph S. Soft power: the means to sucess in world politics. New York: Public Affairs, 2016.

4 LE PRESTRE, Philippe. Ecopolitica Internacional. São Paulo: Senac, 2000. p. 174
}

destaque na Conferência como líder dos países do Sul.

A Conferência de Estocolmo teve como um dos principais resultados a adoção da Declaração de Estocolmo sobre Meio Ambiente e Desenvolvimento Humano, um conjunto de 26 princípios que deveriam orientar as políticas dos Estados com relação ao meio ambiente. A Declaração de Estocolmo refletiu em parte a dicotomia dos debates que marcaram a Conferência, dando especial ênfase à promoção de melhores condições de desenvolvimento aos países do Sul. São vários os princípios que fazem referência à cooperação entre os países desenvolvidos e em desenvolvimento como instrumento de aumento das condições de desenvolvimento desses países e, consequentemente, para uma melhora das condições ambientais, como depreende-se do princípio 11 da Declaração:

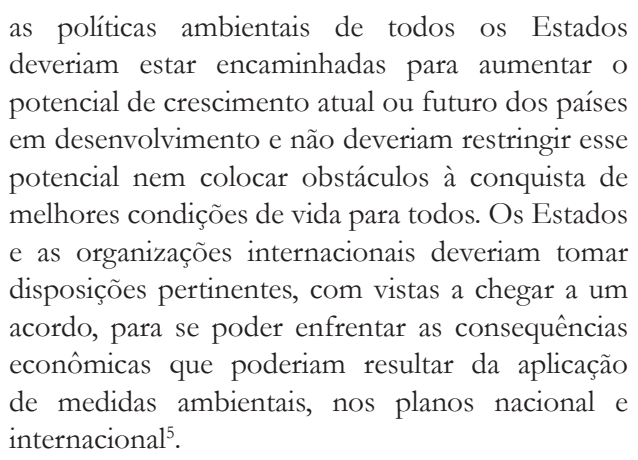

A Declaração de Estocolmo reflete, também, a vontade dos países do Sul em minimizar o alcance desta, conforme relata Le Prestre: "por exigência deles, os princípios 8 e 9 afirmam que o desenvolvimento econômico é uma pré-condição para a melhoria da qualidade de vida e um remédio para a degradação do meio

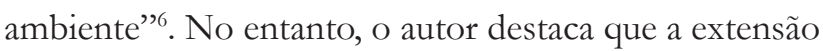
das medidas de cooperação internacional na questão ambiental após Estocolmo foi mais difícil do que o previsto, sobretudo por três questões: 1 . o conhecimento sobre os problemas ambientais era insuficiente; 2 . os custos de proteção ambiental são altos, e logo foram constatadas outras prioridades internacionais, sobretudo econômicas, que esfriaram o ânimo inicial; 3. a tendência das ONGs de se fixarem em fins irrealistas e em projetos grandiosos?

CONFERÊNCIA DAS NAÇÕES UNIDAS. Declaração de Estocolmo sobre o Ambiente Humano. Estocolmo, 1972. Disponível em: http://www.silex.com.br/leis/normas/estocolmo.htm. Acesso em: 20 jun. 2019.

6 LE PRESTRE, Philippe. Ecopolitica internacional. São Paulo: Senac, 2000. p.176.

LE PRESTRE, Philippe. Ecopolitica Internacional. São Paulo: Sen- 
Outro marco importante da Conferência de Estocolmo é o estabelecimento do Programa das Nações Unidas para o Meio Ambiente (PNUMA), sediado em Nairóbi, no Quênia. O PNUMA terá um papel relevante na adoção de tratados multilaterais globais na esfera ambiental ${ }^{8}$.

Duas grandes Conferências das Nações Unidas são realizadas no início da década de 1990 abordando temas que nem sempre ocuparam um protagonismo nas discussões políticas internacionais: meio ambiente e direitos humanos. Em 1992 acontece a Conferência das Nações Unidas sobre Meio Ambiente e Desenvolvimento, realizada no Rio de Janeiro e, em 1993, a Conferência sobre Direitos Humanos, realizada em Viena. Esse destaque alcançado por temas até então marginais é atribuído ao fim da Guerra Fria ${ }^{9}$, que permitiu a criação de um cenário de aproximação entre os Estados para discussão de temas de interesse global, como os direitos humanos e o meio ambiente.

A Conferência do Rio sobre Meio Ambiente e Desenvolvimento é considerada uma verdadeira conferência mundial pelo número de países e representações envolvidas. Foram 178 Estados, oito mil delegados, dezenas de organizações internacionais, três mil representantes de organizações não-governamentais (ONG’s) credenciadas, mais de mil ONG's num fórum paralelo e nove mil jornalistas. $\mathrm{Na}$ sessão final, 103 chefes de Estado e de governo estavam sentados ao redor de uma mesa, o que constitui a maior assembleia de chefes de

ac, 2000. p.178.

8 O Programa das Nações Unidas para o Meio Ambiente (UN Environment) é a principal autoridade ambiental global que define a agenda ambiental global, promove a implementação coerente da dimensão ambiental do desenvolvimento sustentável dentro do sistema das Nações Unidas e serve como um defensor autorizado do meio ambiente global. Nesse sentido, consultar: UN ENVIRONMENT PROGRAMME. About UN environment. Disponível em: https://www.unenvironment.org/pt-br/node/705. Acesso em: 25 jun. 2019.

9 Las relaciones internacionales, tal como se conocieron hasta el fin de la Guerra Fría, correspondieron a una situación que dejó de existir con la desaparición de la Unión Soviética y del mundo socialista. Desde fines de la Segunda Guerra Mundial la arena internacional estuvo dividida en dos bandos enfrentados virtualmente y un tercer espacio compuesto de Estados-naciones que, sin estar directamente comprometidos en esa rivalidad principal, de alguna o de otra manera dependían de lo que ocurriría o dejaba de ocurrir en el conflicto principal. ORTIZ, Eduardo. El estúdio de las relaciones internacionales. Santiago do Chile: Fondo de Cultura Economica, 2004. O conflito principal ao qual se refere o autor é a rivalidade estabelecida entre o bloco capitalista, liderado pelos Estados Unidos e, o bloco comunista, liderado pela então União Soviética. governo e de Estado na história, até a celebração do $50^{\circ}$ aniversário da ONU, no outono de $1995^{10}$. Foram aprovados, durante a realização da Conferência, importantes documentos, entre os quais: a Declaração das Nações Unidas sobre Meio Ambiente e Desenvolvimento, e a Agenda 21.

Em 2002, as Nações Unidas, mais uma vez, convocam os seus Estados membros para uma nova cúpula mundial sobre as questões ambientais. De 26 de agosto a 4 de setembro, os Estados membros da ONU reuniram-se em Johanesburgo, África do Sul, para a realização da Conferência das Nações Unidas sobre Meio Ambiente e Desenvolvimento Sustentável, conhecida também como Rio +10 . Essa Conferência não repercutiu da mesma forma como as suas antecessoras - Estocolmo/1972 e Rio/1992. A Conferência de Johanesburgo foi considerada um fracasso em razão da amplitude dos temas colocados em discussão e pela falta de sistematização na abordagem desses temas.

O foco da Conferência foi colocado nos seguintes pontos: mudança dos padrões de produção e consumo; erradicação da pobreza; manejo de recursos naturais; desenvolvimento sustentável. A expectativa dos participantes estava na elaboração e adoção de três importantes documentos: uma declaração política com compromissos para a implementação do desenvolvimento sustentável; um programa de ação para orientar a efetivação dos compromissos políticos e uma compilação de novos compromissos e iniciativas para ações em esfera nacional e regional. O resultado de Johanesburgo ficou muito aquém do esperado, pois os progressos e o comprometimento com medidas efetivas para a implementação de uma política ambiental internacional foram mínimos ${ }^{11}$.

Em 2012, o Brasil volta a sediar mais uma conferência das Nações Unidas sobre meio ambiente: Conferência das Nações Unidas sobre Desenvolvimento Sustentável ou RIO +20. Passados vinte anos da Conferência do Rio de Janeiro, novamente os Estados integrantes da ONU são chamados a discutir a questão ambiental. A Conferência foi organizada conforme a Resolução 64/236 da Assembleia Geral das Nações

\footnotetext{
10 LE PRESTRE, Philippe. Ecopolitica Internacional. São Paulo: Senac, 2000. P.201.

11 ALBUQUERQUE, Letícia. Conflitos socioambientais na zona costeira catarinense. Tese (Doutorado em Direito) - Programa de Pós-graduação em Direito, Universidade Federal de Santa Catarina. Florianópolis, 2009. p.43.
} 
Unidas entre os dias 20 e 22 de junho de 2012. Reuniu mais de 100 chefes de Estado e governo de forma direta e muitos outros de forma indireta. $\mathrm{O}$ documento final da Conferência - O Futuro que nós queremos - foi marcado pelo compromisso assumido pela comunidade internacional em prol do desenvolvimento sustentável e aprovado pela Assembleia Geral da ONU por meio da Resolução 66/288 de 27 de julho de 2012. O documento reafirma os compromissos assumidos nas conferências anteriores, bem como a necessidade de combate à pobreza e às desigualdades ${ }^{12}$.

É possível concluir que as Conferências das Nações Unidas sobre o Meio Ambiente reforçaram os conflitos potenciais entre o crescimento econômico, a redução da pobreza e a proteção dos ecossistemas frente ao controle da poluição e a conservação dos recursos naturais ou, em outras palavras, entre as necessidades humanas e a conservação dos recursos naturais. De um lado, estavam os países do Sul, reafirmando um direito ao desenvolvimento; de outro, os países do Norte, receosos de perder acesso a mercados em nome de medidas de proteção ambiental. Mesmo que tal discurso tenha alcançado o seu auge na década de 1970, ainda hoje ele faz eco nas discussões sobre o tema ${ }^{13}$.

Por outro lado, em 2015, por ocasião dos 70 anos da ONU, foi adotada pela Assembleia Geral da Organização a chamada AGENDA 2030 para o Desenvolvimento Sustentável ${ }^{14}$. A Agenda consiste em 17 objetivos de desenvolvimento sustentável (os chamados ODS) e 169 metas, que buscam estimular as ações para os próximos anos em áreas consideradas importantes para a humanidade e o planeta: pessoas, planeta, prosperidade, paz e parceria. Guiada pelos propósitos da Carta das Nações Unidas e pela observância do Direito Internacional, a nova agenda reafirma os resultados de todas as grandes conferências e cúpulas das Nações Unidas ${ }^{15}$ que esta-

12 UNITED NATIONS. General Assembly. A/RES/66/288. Disponível em: https://undocs.org/en/A/66/PV.123. Acesso em: 25 jun. 2019.

13 ALBUQUERQUE, Letícia. Conflitos socioambientais na zona costeira catarinense. Tese (Doutorado em Direito) - Programa de Pós-graduação em Direito, Universidade Federal de Santa Catarina. Florianópolis, 2009. p.44.

14 A Agenda 2030 foi adotada pela Assembleia Geral das Nações Unidas, reunida entre os dias 25 e 27 de setembro de 2015, na sede da ONU, em Nova Iorque. Nesse sentido ver: ORGANIZAÇAO DAS NAÇOES UNIDAS. Agenda 2030. Disponível em: https:// nacoesunidas.org/pos2015/agenda2030/. Acesso em: 20 jun. 2019. 15 Estas incluem a Declaração do Rio sobre Meio Ambiente e Desenvolvimento; a Cúpula Mundial sobre o Desenvolvimento beleceram a base para o desenvolvimento sustentável, incluindo as Conferências de Meio Ambiente.

Em 2018, por ocasião das comemorações do dia mundial do meio ambiente, o relator das Nações Unidas sobre as obrigações de direitos humanos relacionadas ao usufruto de um meio ambiente seguro, limpo, saudável e sustentável, John Knox e o chefe do PNUMA Erik Solheim, cobraram o reconhecimento em nível global do direito humano ao meio ambiente saudável e sustentável por parte das Nações Unidas ${ }^{16}$.

No entanto, essa ausência de um reconhecimento expresso por parte das Nações Unidas ao direito humano ao meio ambiente saudável e sustentável não impede que, de forma indireta, de fato, já exista tal reconhecimento. O relatório elaborado pelo Conselho de Direitos Humanos sobre o direito à alimentação e os efeitos dos agrotóxicos, que será examinado a seguir, permite confirmar tal afirmação.

\section{Meio ambiente e direitos humanos: efeitos dos agrotóxicos sobre direitos à saúde e à alimentação adequada}

O relatório especial sobre direito à alimentação do Conselho de Direitos Humanos da ONU, distribuído a 23 de janeiro de 2017, consolida os mais modernos conhecimentos científicos, políticas e práticas relacionados à gestão e controle dos impactos dos agrotóxicos sobre os direitos humanos em âmbito internacional.

Esse instrumento analisa os impactos adversos dos agrotóxicos sobre os direitos humanos levando em con-

Sustentável; a Cúpula Mundial para o Desenvolvimento Social; o Programa de Ação da Conferência Internacional sobre População e Desenvolvimento, a Plataforma de Ação de Pequim; e a Conferência das Nações Unidas sobre Desenvolvimento Sustentável (Rio+20). É considerada também a continuidade dada a estas conferências, incluindo os resultados da Quarta Conferência das Nações Unidas sobre os Países Menos Desenvolvidos, a Terceira Conferência Internacional sobre Pequenos Estados Insulares em Desenvolvimento; a Segunda Conferência das Nações Unidas sobre Países em Desenvolvimento Sem Litoral; e da Terceira Conferência Mundial da ONU sobre a Redução do Risco de Desastres. ORGANIZAÇAO DAS NAÇOES UNIDAS. Agenda 2030. Disponível em: https:// nacoesunidas.org/pos2015/agenda2030/. Acesso em: 20 jun. 2019. 16 ONU BRASIL. Relator e chefe ambiental da onu cobram reconbecimento do direito bumano a um planeta saudável. Disponível em: https:// nacoesunidas.org/relator-e-chefe-ambiental-da-onu-cobram-reconhecimento-do-direito-humano-a-um-planeta-saudavel/. Acesso em: 5 jun. 2018. 
ta os impactos sobre a saúde humana e o meio ambiente, e relacionando-os a direitos consagrados em tratados internacionais, em especial os direitos humanos à alimentação adequada, à saúde, às plenas condições de desenvolvimento das crianças, à proteção da maternidade e integridade física e psíquica de mães grávidas. Esses impactos à saúde humana se apresentam em diversos âmbitos e em diferentes graus e formas de contaminação sobre agricultores e trabalhadores rurais, pessoas que vivem em comunidades situadas próximo a áreas agrícolas, comunidades indígenas, mulheres grávidas, crianças e, de um modo geral, consumidores de mercados situados em todo o mundo.

Levando em conta todo esse quadro de diferentes formas de exposição, os agrotóxicos são responsáveis por 200.000 (duzentos mil) casos de mortes associadas a envenenamento por ano, sendo noventa e nove por cento desses casos nos países em desenvolvimento, demonstrando que determinados grupos são expostos a risco mais elevado de terem seus direitos à saúde de alimentação violados, causando, ainda, custos substanciais aos governos e efeitos catastróficos sobre o meio ambiente. Nas últimas duas décadas, diversos desastres envolvendo contaminação por agrotóxicos em países em desenvolvimento ilustram bem essa realidade factual. Uma das razões está no fato de que, embora esses países sejam responsáveis por, apenas, uma quarta parte dos agrotóxicos utilizados no mundo, regulamentações ambientais fracas e pouco implementadas e fiscalizadas permitem que recebam os produtos de maior toxicidade, muitas vezes banidos em seus países de origem.

A exposição crônica a agrotóxicos perigosos tem sido associada à ocorrência de câncer e doenças de Alzheimer e Parkinson, disfunção hormonal, problemas no desenvolvimento humano e infertilidade. Além disso, diversos efeitos neurológicos como perda de memória, diminuição de coordenação, redução da habilidade visual e redução das capacidades motoras, e problemas como asma e alergias estão associadas à contaminação crônica por agrotóxicos, embora esses efeitos crônicos possam manifestar-se muitos meses ou anos após a exposição.

Mesmo tendo sido estabelecida uma clara relação desses graves riscos à saúde humana com diversos agrotóxicos, as negativas sistemáticas da indústria agroquímica e suas táticas agressivas e antiéticas de marketing permitem que esses produtos continuem sendo utili- zados, muito embora o risco de contaminação possa persistir por décadas no meio ambiente e persistir se acumulando em fontes de alimento ${ }^{17}$. Isto é preocupante também com relação aos 'ingredientes inertes', geralmente utilizados para melhorar a efetividade do princípio ativo, que podem não ser testados e nem mesmo informados nos rótulos das embalagens, e ainda mais porque o efeito sinergético e combinado da exposição a diversos agrotóxicos no alimento, solo, água e ar ainda não foi adequadamente estudado.

Os agricultores e trabalhadores rurais estão sujeitos aos índices mais elevados de exposição, ainda que atendendo, adequadamente, as recomendações de segurança. Essa situação é agravada peça falta de treinamento em segurança e de infraestrutura e recursos dos governos para regular e monitorar esses procedimentos. A situação é particularmente grave quando envolve o trabalho infantil, especialmente considerando que 60 por cento do trabalho infantil se dá na agricultura, em especial nos países em desenvolvimento. A falta de instrumentos de segurança adequados e de experiência, e especialmente a maior sensibilidade das crianças aos malefícios dos agrotóxicos, torna essa situação alarmante. Trabalhadores sazonais e imigrantes também são mais suscetíveis à exposição devido à dificuldade de compreensão de rótulos, ao acesso a equipamentos de segurança e a tratamento médico, além da sua falta de controle na escolha dos produtos a serem utilizados.

Pessoas que vivem em comunidades situadas próximas a áreas agrícolas experimentam grave risco de exposição, em especial associado à pulverização aérea. Essa prática vem ganhando grande atenção e sendo objeto de inúmeros debates e até proibições legais no Brasil, devido ao grande risco que a atividade oferece devido à imprevisibilidade do carreamento das substâncias pelo vento, o que vem causando diversos acidentes, cabendo destacar o acidente decorrente da pulverização que atingiu a Escola Municipal Rural São José do Ponta, no Município de Rio Verde, Estado do Goiás, em que mais de cem (100) pessoas entre crianças, professores e pais foram contaminadas ${ }^{18}$. Populações pobres, atraídas pelo

17 UNITED NATIONS. General Assembly. A/HRC/34/48. Human Rights Council. Report of the Special Rapporteur on the right to food. Disponível em: http://ap.ohchr.org/documents/dpage_e. aspx?si=A/HRC/34/48. Acesso em: 21 jun. 2019.

18 FREITAS, Cleuton César Ripol de. A Pulverização Aérea na Escola Rural São José do Pontal: uma abordagem dos fatos e suas circunstâncias. In: SOUSA, Murilo Mendonça Oliveira de; FOLGADO, Cleber Adriano Rodrigues (org.). Agrotóxicos: violações socio- 
valor mais baixo destas propriedades, estão mais sujeitas e sofrem os efeitos da contaminação de forma mais intensa quando combinados à má nutrição. Os impactos às águas superficiais e subterrâneas, que pode persistir por décadas após a interrupção do uso desses produtos, também sujeita essas populações à contaminação crônica, o que é, ainda, mais grave no caso de comunidades indígenas que têm sua subsistência tradicional e cultura intrinsecamente associadas à terra e aos recursos naturais onde vivem.

A proteção à maternidade, às mulheres grávidas e às crianças é objeto de especial atenção no relatório especial sobre direito à alimentação do Conselho de Direitos Humanos da ONU, que destaca de imediato a maior vulnerabilidade de crianças aos efeitos dos agrotóxicos seja porque seus órgãos ainda se encontram em desenvolvimento, seja porque são expostas a uma quantidade maior de contaminação por unidade de peso, além do fato de que crianças possuem menos enzimas capazes de evitar e recuperar os danos causados por agrotóxicos. Os impactos à saúde das crianças incluem desenvolvimento intelectual diminuído, efeitos comportamentais adversos e outras anormalidades, ainda que, em pequenas doses, a contaminação, seja pelo carreamento de resíduos de agrotóxicos pelo vento, seja pelo consumo, pode prejudicar a saúde das crianças interrompendo seu crescimento psicológico e físico, levando a uma vida de problemas de saúde e complicações.

Em mulheres grávidas, a exposição a agrotóxicos aumenta o risco de abortos, nascimento prematuro e problemas de nascença. A exposição pré-natal é comprovada por estudos que já constaram a presença de agrotóxicos no cordão umbilical, assim como no leite materno, e é de extrema gravidade, podendo causar leucemia e outros tipos de câncer, autismo e problemas respiratórios, além de afetar o desenvolvimento do sistema nervoso do feto e seu sistema imunológico ${ }^{19}$.

Os consumidores estão expostos aos riscos decorrentes da existência em fontes de alimento animal e vegetal de uma ampla gama de resíduos de agrotóxicos, um verdadeiro coquetel de substâncias que podem interagir de forma sinergética elevando o nível de toxicidade

ambientais e direitos humanos no Brasil. Anápolis: Universidade de Goiás, 2016. p. 99.

19 UNITED NATIONS. General Assembly. A/HRC/34/48. Human Rights Council. Report of the Special Rapporteur on the right to food. Disponível em: http://ap.ohchr.org/documents/dpage_e. aspx?si=A/HRC/34/48. Acesso em: 21 jun. 2019. p. 7-8. das substâncias. Além disso, os agrotóxicos sistêmicos impedem a sua remoção pela lavagem dos alimentos, que ainda podem ter sua toxicidade aumentada pelas formas de cozimento dos alimentos. Essas substâncias ainda possuem efeito bioacumulativo contaminando ovos e leite, que são alimentos básicos da dieta humana, e até mesmo recursos pesqueiros, causando significativos riscos a pessoas que dependem do consumo de pescado.

Sobre o meio ambiente, os impactos do uso de agrotóxicos vão desde a ameaça aos sistemas ecológicos à contaminação do solo e das águas subterrâneas, à degradação dos solos, ao prejuízo aos organismos não alvo (prejuízos esses subestimados), chegando, até mesmo, a ameaçar os serviços ecossistêmicos vitais (como o equilíbrio ecológico e controle biológicos de pragas), causando, também, prejuízos a invertebrados benéficos e a pássaros, borboletas e outros animais silvestres e polinizadores naturais.

Acerca dos danos aos polinizadores, em especial às abelhas, químicos neonicotinóides são apontados em todo o mundo como responsáveis pela Desordem do Colapso das Colônias (DCC). O declínio de cinquenta por cento da população de abelhas nos últimos vinte e cinco anos nos Estados Unidos e Grã-Bretanha tem sido atribuído à aplicação de inseticidas, ameaçando as bases da agricultura, já que setenta e um por cento das culturas que provêm a quase totalidade da alimentação mundial dependem da polinização de abelhas.

Além disso, os pesticidas sistêmicos, introduzidos em organismos geneticamente modificados e que correspondem a cerca de sessenta por cento da exposição diária a essas substâncias ainda carecem de estudos mais aprofundados sobre a saúde humana, insetos benéficos, o solo, os ecossistemas e a vida aquática. Essa situação é particularmente grave se levado em conta o caso do glifosato, apresentado pela indústria, inicialmente, como menos tóxico e persistente que outros herbicidas e que, em 2015, veio a ser considerado como provavelmente cancerígeno pela Organização Mundial da Saúde (OMS).

Outra questão associada é a disparidade na aplicação do Princípio da Precaução em diferentes regiões. Enquanto, na Europa, a existência de uma suspeita de risco de causar malefícios à saúde e ao meio ambiente atribui ao interessado o ônus de comprovar que o produto não é nocivo, nos Estados Unidos, a realidade é 
outra: o Princípio da Equivalência Substancial permite que uma nova substância seja colocada no mercado sem a necessidade de estudos mais aprofundados, contanto que guarde similaridade adequada com outra substância já autorizada ${ }^{20}$. Essas diferenças de aplicação do Princípio da Precaução corroboram uma das recomendações centrais do relatório, no sentido da adoção de regulações internacionais acerca da autorização e uso de agrotóxicos que levem em conta seriamente o princípio da precaução.

O direito à alimentação adequada garante alimento necessário a alcançar um padrão adequado de vida, relacionando-se, portanto, à garantia básica da dignidade da pessoa humana amparado na Declaração Universal dos Direitos Humanos. No âmbito da Convenção Internacional sobre Direitos Econômicos, Sociais e Culturais, o respectivo Comitê considerou que o direito à alimentação adequada "não deve ser construído em um sentido raso on restritivo" ${ }^{21}$ e que o termo 'adequado' denota não apenas quantidade, mas também qualidade, destacando, ainda, que a noção de sustentabilidade está intrinsecamente relacionada à ideia de alimento adequado e que esteja acessível às presentes e futuras gerações.

O relatório do Conselho de Direitos Humanos destaca, ainda, que os agrotóxicos ameaçam a produção futura de alimentos — inclusive em sua quantidade — na medida em que são responsáveis pela perda de biodiversidade, contaminação dos solos e águas e por afetar, negativamente, a produtividade de terras agriculturáveis.

A proteção da saúde humana também é prevista no art. 12 da Convenção Internacional sobre Direitos Econômicos, Sociais e Culturais que atribui aos Estados o dever de prover a seus cidadãos os mais altos níveis de saúde, o que se estende aos meios necessários para tanto: alimento seguro, água potável, condições de trabalho seguras e o meio ambiente equilibrado. A Convenção pela Eliminação de Todas as Formas de Discriminação contra as Mulheres assegura às mulheres o direito à saúde e segurança e proteção especial às mães antes e após o nascimento de seus filhos. A Convenção sobre os Di-

20 UNITED NATIONS. General Assembly. A/HRC/34/48. Human Rights Council. Report of the Special Rapporteur on the right to food. Disponível em: http://ap.ohchr.org/documents/dpage_e. aspx?si=A/HRC/34/48. Acesso em: 21 jun. 2019. p. 9-10

${ }_{21}$ UNITED NATIONS. General Assembly. A/HRC/34/48. Human Rights Council. Report of the Special Rapporteur on the right to food. Disponível em: http://ap.ohchr.org/documents/dpage_e. aspx?si=A/HRC/34/48. Acesso em: 21 jun. 2019. p. 11. reitos das Crianças protege o desenvolvimento infantil de maneira saudável com disposição específica acerca da proteção de contaminação ambiental.

Outros instrumentos internacionais de direitos humanos, como a Convenção Internacional de Direitos Civis e Políticos, a Declaração das Nações Unidas sobre os Direitos dos Povos Indígenas, possuem disposições que obrigam os Estados a adotarem medidas de proteção, informação e reparação acerca do uso de agrotóxicos. No entanto, as dificuldades de implementação e efetividade seguem sendo os maiores desafios ${ }^{22}$.

No âmbito do Direito Ambiental Internacional, esta é uma realidade premente, na medida em que existem mais de 500 tratados internacionais de alguma forma relacionados ao meio ambiente. Contudo, ainda assim, a escassez dos recursos a degradação seguem sendo dilemas presentes e que vem se agravando, estando claramente estabelecido que "o desafio primário reside na implementação e cumprimento dos compromissos e legislações já existentes" ${ }^{23}$.

Ainda assim, no caso dos agrotóxicos, inexiste um tratado internacional em matéria ambiental, havendo, apenas, certas restrições e limitações impostas por acordos como o Protocolo de Montreal, e Convenção de Viena para a Proteção da Camada de Ozônio, e Convenção de Estocolmo sobre Poluentes Orgânicos Persistentes (que acabou restringindo o uso de determinados agrotóxicos), os quais cobrem, apenas, um espectro limitado de substâncias deixando um grande número de agrotóxicos fora de seus escopos. Dessa forma, o direito internacional carece de um instrumento que regule os diferentes tipos de agrotóxicos perigosos levando em conta todo o seu ciclo de vida.

Além disso, o Protocolo de Montreal e a Convenção de Estocolmo abrigam, apenas, uma pequena parcela das substâncias deixando sem qualquer limitação pela lei internacional a vasta maioria dos agrotóxicos perigosos. Outros instrumentos, como a Convenção de Rotterdam, permitem a obstrução sobre a restrição de determinados químicos como o Paraquat ${ }^{24}$, que tem seu

22 UNITED NATIONS. General Assembly. A/HRC/34/48. Human Rights Council. Report of the Special Rapporteur on the right to food. Disponível em: http://ap.ohchr.org/documents/dpage_e. aspx?si=A/HRC/34/48. Acesso em: 21 jun. 2019. p. 12.

23 JENDROSKA, Jerzy; BAR, Magdalena. Procedural Enviromental Rights: Principle X In Thepry and Practice. Cambridge: Intersentia Ltd, 2017. p. 261.

${ }^{24}$ UNITED NATIONS. General Assembly. A/HRC/34/48. Hu- 
uso banido em diversos países, mas é exportado para países em desenvolvimento.

Em todo o mundo, as políticas e limites estabelecidos pelos países para reduzir os prejuízos causados pelos agrotóxicos variam significativamente. Em comum a esses países, existe uma grande dificuldade em avaliar os riscos relacionados aos agrotóxicos submetidos à aprovação, assim como uma limitada preocupação e análise sobre os já conhecidos diversos efeitos crônicos à saúde, além da falta de periodicidade nas reavaliações e da enorme pressão exercidas pelas companhias para evitar ou reverter o banimento de agrotóxicos perigosos ${ }^{25}$.

A maioria dos países possui índices de controle de resíduos de agrotóxicos nos alimentos. No entanto, há falhas na capacidade de inspeção desses limites e ausência de sistemas adequados de medição para assegurar o respeito a esses limites máximos. Além do mais, como os limites nos diferentes países não são uniformes "alimentos banidos em um país podem continuar tendo sua entrada admitida em outros que permitam índices mais elevados de resíduos" ${ }^{26}$.

A falta de um instrumento internacional de regulação da produção e uso de agrotóxicos contribui para que agrotóxicos banidos e altamente tóxicos sejam usados largamente em países em desenvolvimento simplesmente "porque são alternativas mais baratas" de modo que em muitos casos "agrotóxicos altamente perigosos que não têm uso permitidos em países industrializados são exportados para paises em desenvolvimento" ${ }^{27}$, prática que, muitas vezes, se 'justifica' pela necessidade das empresas de esvaziarem seus estoques após não conseguirem renovar seus registros nos países de origem. Analisando essa situação sob a perspectiva dos direitos humanos, o relatório destaca: "Submeter indivíduos de outras nações a toxinas que sabidamente causam enormes prejuízos à saúde e até fatalidades é uma clara

man Rights Council. Report of the Special Rapporteur on the right to food. Disponível em: http://ap.ohchr.org/documents/dpage_e. aspx?si=A/HRC/34/48. Acesso em: 21 jun. 2019. p. 14.

25 UNITED NATIONS. General Assembly. A/HRC/34/48. Human Rights Council. Report of the Special Rapporteur on the right to food. Disponível em: http://ap.ohchr.org/documents/dpage_e. aspx?si=A/HRC/34/48. Acesso em: 21 jun. 2019. p. 16.

26 UNITED NATIONS. General Assembly. A/HRC/34/48. Human Rights Council. Report of the Special Rapporteur on the right to food. Disponível em: http://ap.ohchr.org/documents/dpage_e. aspx?si=A/HRC/34/48. Acesso em: 21 jun. 2019. p. 16.

27 UNITED NATIONS. General Assembly. A/HRC/34/48. Human Rights Council. Report of the Special Rapporteur on the right to food. Disponível em: http://ap.ohchr.org/documents/dpage_e. aspx?si=A/HRC/34/48. Acesso em: 21 jun. 2019. p. 16. violação de direitos humanos" 28 .

Diante desse quadro, o relatório faz especial consideração à grande oportunidade que a agroecologia oferece como alternativa ao modelo do uso intensivo de agrotóxicos. A prática da agricultura orgânica é uma realidade e estudos indicam que a agroecologia é capaz de alimentar toda a população mundial assegurando que ela pode ser adequadamente nutrida. Esse modelo alternativo de agricultura sustentável substituiu o químico pelo biológico, estimula práticas agrícolas mais adaptadas ao ambiente local e promove a fertilidade e saúde do solo em longo prazo, juntamente ao incremento da diversidade no campo e ao distanciamento de monocultivos de poucas espécies.

A agroecologia previne a exposição a substâncias tóxicas, permite a preservação dos serviços ecossistêmicos, como o controle natural de pragas, e promove a melhora da qualidade do ar, solo e das águas superficiais e subterrâneas ajudando, ainda, a mitigar os efeitos das mudanças climáticas reduzindo as emissões de gases de efeito estufa.

As conclusões do relatório apontam, fortemente, para a necessidade de criação de um instrumento internacional de caráter vinculativo que assegure respeito e proteção aos direitos humanos à alimentação adequada e saúde fortalecendo a aplicação do Princípio da Precaução e, principalmente, proíba a prática ainda recorrente de exportação de agrotóxicos banidos em seus países e continentes de origem, para serem usados em terceiros países. Analisar os agrotóxicos, na perspectiva dos direitos humanos, demanda reconhecer universalidade e não discriminação a todas as pessoas, inclusive os grupos vulneráveis, que suportam, desproporcionalmente, os ônus dos agrotóxicos perigosos ${ }^{29}$.

Uma das recomendações do relatório consiste, ainda, na necessidade de cooperação entre os órgãos responsáveis da agricultura, saúde pública e meio ambiente, a agirem de forma eficiente para evitar os impactos adversos dos agrotóxicos e mitigar os riscos relacionados ao

28 UNITED NATIONS. General Assembly. A/HRC/34/48. Human Rights Council. Report of the Special Rapporteur on the right to food. Disponível em: http://ap.ohchr.org/documents/dpage_e. aspx?si=A/HRC/34/48. Acesso em: 21 jun. 2019. p. 17.

29 UNITED NATIONS. General Assembly. A/HRC/34/48. Human Rights Council. Report of the Special Rapporteur on the right to food. Disponível em: http://ap.ohchr.org/documents/dpage_e. aspx?si=A/HRC/34/48. Acesso em: 21 jun. 2019. p. 21-22. 
seu uso indevido e intensivo ${ }^{30}$. Este é, no entanto, um dos retrocessos que a legislação brasileira se encontra sob ameaça de experimentar dentro do amplo e intenso processo de retrocesso ambiental em que se encontra inserido o país.

\section{Brasil e as políticas de liberação de agrotóxicos: ecocídio consentido?}

Os Estados nações sempre mantiverem relações entre si, seja para auxílio mútuo como também pela presença constante de conflitos. Todavia, atualmente, nessas relações, tem-se um novo ator no cenário das relações internacionais, que têm exercido grande influência nos processos decisórios: as corporações transnacionais. O Estado deixa de ser o ente absoluto para ser influenciado pela força do capital das corporações transnacionais ${ }^{31}$.

As relações internacionais estão permeadas pela interdependência, em que há uma dependência mútua entre os países e/ou os atores internacionais. Logo, nessa interdependência há efeitos recíprocos, ou seja, custos recíprocos que se manifestam na redução de autonomia dos participantes. Países com menos dependências podem utilizar desta como fonte de poder, ora, por não se encontram em posição tão vulnerável, perfazendo uma relação desequilibrada ${ }^{32}$.

Analisando essa característica da interdependência nesses novos atores internacionais, temos que as corporações multinacionais ou transnacionais também se utilizam desse mecanismo desequilibrado para manifestar seu poder e influenciar, de modo decisivo, as políticas internacionais e até mesmo internas de países mais vulneráveis.

30 UNITED NATIONS. General Assembly. A/HRC/34/48. Human Rights Council. Report of the Special Rapporteur on the right to food. Disponível em: http://ap.ohchr.org/documents/dpage_e. aspx?si=A/HRC/34/48. Acesso em: 21 jun. 2019. p. 23.

31 Nesse sentido ver: VEIGA, João Paulo Cândia; RODRIGUES, Pietro Carlos. Transnational arenas, public policies and the environment: the case of palm in the Amazon. Ambient. soc. São Paulo, v. 19, n. 4, p. 1-20, Dec. 2016. Disponivel em: http://www.scielo.br/ scielo.php?script $=$ sci_arttext\&pid $=S 1414753$ X2016000400002\&ln $\mathrm{g}=$ en\&nrm=iso. Acesso em: 30 jun. 2019.

32 LIMA, Juliana Schmitz Paes de. Interdependência e os organismos internacionais. In: OLIVEIRA, Odete Maria de; RI JÚNIOR, Arno dal (org.). Relações Internacionais: interdependência e sociedade global. Ijuí: Unijuí, 2003. p. 371-392.
Há uma nova ordem mundial com a concentração de poder em organizações multinacionais, perpetrando um jogo de interesses econômicos entre Estados, via as instituições oficiais, porém com os interesses das corporações transnacionais e multinacionais como pano de fundo. Nesse cenário se inserem graves violações a direitos humanos perpetrados por empresas multinacionais e transnacionais em busca de seus lucros e interesses privados.

Essas violações de direitos humanos, especificamente quanto ao direito a um meio ambiente sadio e qualidade de vida e saúde, são frequentes, observando a atual política das grandes corporações de destinar seus passivos ambientais para países mais vulneráveis economicamente. A deslocalização da poluição química é prática corriqueira, em que os países do Sul Global, África e Ásia recebem os rejeitos tóxicos, produtos químicos, herbicidas e pesticidas, que foram proibidos em seus países de origem, sendo exportados para abastecer a indústria química apenas trocando o nome do produto ${ }^{33}$.

Apenas na África são documentados estoques de agrotóxicos obsoletos armazenados em péssimas condições. A Organização para a Alimentação e Agricultura das Nações Unidas estima que existem mais de 100.000 toneladas de pesticidas obsoletos nos países em desenvolvimento, ou porque se deterioraram ou porque foram proibidos.

O problema é mais bem documentado na África e no Oriente Médio, onde não há um único país afetado pelos riscos ambientais graves associados com pesticidas obsoletos. São estimados em cerca de 20.000 toneladas deles somente na África. Alguns estoques são mais de 30 anos de idade, e são mantidos em condições precárias, com poucas ou nenhumas precauções de segurança. ${ }^{34}$

Ao todo, a Organização para a Alimentação e Agricultura das Nações Unidas estima que existem mais de 100.000 toneladas de pesticidas obsoletos nos países em desenvolvimento, em geral, restos de pesticidas que não podem mais ser usados, porque eles se deterioraram por meio de

\footnotetext{
33 ALBUQUERQUE, Letícia. Poluentes orgânicos persistentes: uma análise da Convenção de Estocolmo. Curitiba: Juruá, 2006.

34 The problem is best documented in Africa and the Near East, where there is not a single country unaffected by the serious environmental hazards associated with obsolete pesticides. There are estimated to be some 20,000 tonnes of them in Africa alone. Some stocks are over 30 years old, and are kept in poor conditions with few or no safety precautions. WODAGENEH, Alemayehu. Trouble in Store. In: Our Planet, Chemicals, March, 1997. Disponível em: http://www.ourplanet.com/imgversn/86/woda.html. Acesso em: 25 ago. 2016.
} 
armazenamento prolongado, ou que tenham sido proibidos enquanto ainda na loja. As ações incluem grandes quantidades de compostos organoclorados altamente persistentes como o DDT, dieldrina e $\mathrm{HCH}$, bem como compostos organofosforados altamente tóxicos. ${ }^{35}$

Ainda imersos em uma história de neocolonialis$\operatorname{mos}^{36}$, em que a natureza virou mercadoria, a agricultura é criada artificialmente e cuidada quimicamente e as decisões políticas acerca da produção de alimentos são comandadas pelos oligopólios, beneficiadas pela drástica redução do Estado com endeusamento do livre comércio, o Brasil parece ser uma das principais economias do mundo, a ser usurpada.

Justifica-se, então, o cenário brasileiro alarmante do maior consumidor de agrotóxicos do mundo, o terceiro maior exportador agrícola de commodities e também o maior consumidor de agrotóxicos do mundo. Sua participação no consumo representa (um quinto) dos agrotóxicos mundiais e $86 \%$ (oitenta e seis por cento) de toda a América Latina ${ }^{37}$.

Se já não bastasse esses índices, desde o começo do ano de 2019, em 175 dias, o governo brasileiro liberou o registro 211 agrotóxicos ${ }^{38}$, sendo a maior liberação já realizada no Brasil desde os anos de $2005^{39}$. Uma das justificativas do governo para essa liberação é uma suposta medida de desburocratização, visto que pesticidas das empresas Dow Agrosciences, Bayer e Syngenta

35 In all, the Food and Agriculture Organization of the United Nations estimates, there are more than 100,000 tonnes of obsolete pesticides in developing countries, generally left-over pesticides that can no longer be used because they have deteriorated through prolonged storage, or have been banned while still in store. The stocks include large amounts of highly persistent organochlorine compounds such as DDT, dieldrin and $\mathrm{HCH}$, as well as highly toxic organophosphorous compounds. They are now regarded as hazardous waste. WODAGENEH, Alemayehu. Trouble in Store. 1997. Disponível em: http://www.ourplanet.com/imgversn/86/woda.html. Acesso em: 25 ago. 2016.

36 CARNEIRO, Fernando Ferreira (org.). Dossiê ABRASCO: um alerta sobre os impactos dos agrotóxicos na saúde. Rio de Janeiro: EPSJV; São Paulo: Expressão Popular, 2015. Disponível em: http://www.abrasco.org.br/dossieagrotoxicos/wp-content/uploads/2013/10/DossieAbrasco_2015_web.pdf. Acesso em: 10 jul. 2016.

37 BOMBARDI, Larissa Mies. Geografia do uso de agrotóxicos no Brasil e conexões com a União Europeia. São Paulo: Fflch - Usp, 2017.

38 DIÁRIO OFICIAL DA UNIÃO. Ato nº 24, de 9 de abril de 2019. Brasília.

39 GAUCHAZH (ed.). Liberação de agrotóxicos no Brasil é a maior em 14 anos. 2019. Disponível em: https://gauchazh.clicrbs.com.br/economia/campo-e-lavoura/noticia/2019/06/liberacao-de-agrotoxicos-no-brasil-e-a-maior-em-14-anos-cjwjs4f1203at01oi1 ew0o9en. html. Acesso em: 20 jun. 2019. aguardavam liberação há mais de quatro anos. Outra justificativa é que a liberação era de ingredientes genéricos de substâncias e produtos já disponíveis no mercado, o que possibilitaria um barateamento dos preços dos “defensivos" no país, já que teria maior concorrência ${ }^{40}$.

Essa justificativa do barateamento é desmentida quando se analisa que a própria ANVISA afirma que as grandes corporações químicas não competem entre si, mantendo seu monopólio ${ }^{41}$ sobre os produtos "as dez maiores indústrias não competem entre si [...] mesmo no caso em que as patentes estão vencidas, tirando raras exceções, as empresas focam a produção em agrotóxicos com ingredientes ativos que não são comercializados pelas demais empresas, o que gera uma espécie de monopólio sobre os produtos". ${ }^{42}$

Todavia, nessa nova lista de liberação de registro de agrotóxicos publicada no Diário Oficial da União em 24 de junho de 2019, há um novo ingrediente ativo, o Florpirauxifen-benzil, produzido pela Dow, herbicida classificado como medianamente tóxico à saúde humana e classificado como perigoso ao meio ambiente ${ }^{43}$. Mais do que isso, nessa onda de liberações, embora se afirme que a liberação é de cópias de ingredientes ativos que já estão no mercado, o fator preocupante é que 48\% dos agrotóxicos liberados são altamente tóxicos à população e muito perigosos à natureza ${ }^{44}$.

40 REUTERS. Ministério da Agricultura aprova registro de mais 42 agrotóxicos, totalizando 211 no ano. 2019. Disponível em: https:// g1.globo.com/economia/agronegocios/noticia/2019/06/24/ ministerio-da-agricultura-aprova-registro-de-mais-42-agrotoxicostotalizando-211-no-ano.ghtml. Acesso em: 20 jun. 2019.

${ }^{41}$ Esse monopólio é exercido por seis empresas transnacionais que controlam sozinha $60 \%$ do mercado brasileiro, sendo as empresas Syngenta, Monsanto e Bayer, Dow, Basf, Milenia, de acordo com as vendas mundiais do ano de 2013. Esses dados sofreram alterações, visto as fusões de empresas e a participação massiva atual da China no mercado dos agrotóxicos. BOMBARDI, Larissa Mies. Pequeno ensaio cartográfico sobre o do uso de agrotóxicos no Brasil. São Paulo: Laboratório de Geografia Agrária - Usp, 2016. p. 27.

42 AGÊNCIA Nacional de Vigilância Sanitária. 2012. Disponível em: http://portal.anvisa.gov.br/resultado-de- busca?p_p_ $\mathrm{id}=101 \&$ p_p_lifecycle $=0 \&$ p_p_state $=$ maximized $\&$ p_P_ mode= view\&p_P_col_id=column-1\&p_P_col_count $=1 \& \_101$ struts_action $=\% 2$ Fasset_publisher $\% 2$ Fview_content\&_101_ assetEntryId=2665456\&_101_type = content\&_101_ groupId=219201\&_101_urlTitle $=$ seminario-volta-a-discutir-mercado-de-agrotoxicos-em-2012\&inheritRedirect $=$ true

43 REUTERS. Ministério da Agricultura aprova registro de mais 42 agrotóxicos, totalizando 211 no ano. 2019. Disponível em: https:// g1.globo.com/economia/agronegocios/noticia/2019/06/24/ ministerio-da-agricultura-aprova-registro-de-mais-42-agrotoxicostotalizando-211-no-ano.ghtml. Acesso em: 20 jun. 2019.

44 GAUCHAZH (ed.). Liberação de agrotóxicos no Brasil é a maior em 
Antes mesmo de toda a liberação de registro de agrotóxicos, 30\% (trinta por cento) dos ingredientes ativos utilizados no Brasil são proibidos na União Europeia, cuja vedação é baseada em estudos científicos que já comprovaram os riscos e nocividades desses ativos ${ }^{45}$.

$\mathrm{Na}$ onda de liberações, por certo e mais uma vez, o governo se liberou do encargo de reavaliar e banir importantes ingredientes, como o glifosato produzido pela empresa Monsanto, agora Bayer. Diferentemente da marcha de muitos países europeus pela tentativa de não utilização desse agrotóxico, impulsionados pela condenação da Corte Americana que determinou que a empresa Monsanto, intencionalmente, manipulou documentos e pesquisas para esconder o risco de câncer do glifosato. Embora se tenha noção desse crime cometido, em que empresas como Bayer e Monsanto, DowDuPont e outras corporações estão exterminando com a vida selvagem, com a qualidade da água e com a sustentabilidade da produção de alimentos, as legislações continuam permitindo e, ainda, tornando mais fortes suas habilidades de influenciar as decisões políticas em benefícios de seus interesses privados ${ }^{46}$.

E esses índices permanecem em franco aumento, capitaneados pelos grupos transnacionais do mercado de agrotóxicos, em um grande favorecimento, os governos pautam suas estratégias e políticas públicas na facilitação da expansão e consolidação dessa grande empresa capitalista de apropriação privada da natureza e permissividade no envenenamento da vida.

Outras medidas, de desmonte da proteção socioambiental frente aos efeitos nefastos de determinados agrotóxicos, são emblemáticas, como: a extinção do Ministério do Desenvolvimento Agrário (MDA); o enfraquecimento e esvaziamento dos órgãos reguladores; a nomeação de cargos da gestão pública a representantes do setor privado com evidente conflito de interesses; a aceleração do trâmite do projeto de Lei $n^{\circ}$ 6.299/02 que revoga a Lei $n^{\circ} 7.802 / / 89$ que dispõe sobre comércio, registro, produção e demais atividades atinentes aos

14 anos. 2019. Disponível em: https://gauchazh.clicrbs.com.br/economia/campo-e-lavoura/noticia/2019/06/liberacao-de-agrotoxicos-no-brasil-e-a-maior-em-14-anos-cjwjs4f1203at01oi1ew0o9en. html. Acesso em: 20 jun. 2019.

45 BOMBARDI, Larissa Mies. Geografia do uso de agrotóxicos no Brasil e conexões com a União Europeia. São Paulo: Fflch - Usp, 2017.

46 GILLAM. The Guardian Carey (ed.). Who is paying for Monsanto's crimes? We are. 2019. Disponível em: https://www.theguardian. $\mathrm{com} /$ commentisfree/2019/mar/30/who-is-paying-for-monsantoscrimes-we-are. Acesso em: 20 jun. 2019. agrotóxicos e flexibiliza a regulamentação desses produtos no país; bem como alteração e flexibilização de outras legislações relacionadas a temática ambiental e dos agrotóxicos; a extinção do Conselho Nacional de Segurança Alimentar e Nutricional (Consea), e outras medidas.

Frente a esses retrocessos, não se pode olvidar que, quando se trata do Princípio de Desenvolvimento Sustentável, não se está protegendo, apenas, a natureza e seus correlatos habitantes, mas a proteção do futuro, das gerações futuras e de seus direitos à vida e à saúde ${ }^{47}$, nesse sentido Prieur alerta que:

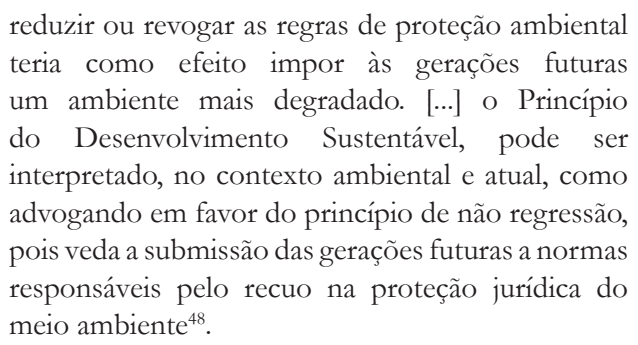

O Princípio de Desenvolvimento Sustentável não pode ser, apenas, uma integração entre os aspectos ambientais, econômicos e sociais, uma visão simplória de ser o equilíbrio desses três aspectos. Sustentabilidade significa respeitar as funções como prioridade, bem como se respeitar limites ecológicos. Quando se entende que alguns interesses são mais essenciais, não se pode mais balancear com o mesmo peso. O desenvolvimento sustentável deve ser um princípio geral de direito alcançado a partir de uma governança internacional e nacional transparente e da implementação de leis ambientais. ${ }^{49}$

A geração atual já tem sofrido com os efeitos nefastos da contaminação por agrotóxicos, onde o poder público entende razoável atribuir um valor de consumo diário, Ingestão Diária Aceitável (IDA), que consiste em um envenenamento gradativo, pois muitos dos agrotó- 
xicos utilizados no Brasil têm efeitos de desregulamentação endócrina ${ }^{50}$, cuja doença não vem pela dose, mas pela exposição. Dessa forma, se conclui que não existe dose segura quando se fala na desregulamentação endócrina ${ }^{51}$.

Mais do que isso, o Limite Máximo de Resíduo (LMR) nos alimentos regulamentados pela legislação brasileira são alarmantes quando comparados com a legislação da União Europeia. Questiona-se porque os brasileiros consomem alimentos com mais resíduos de agrotóxicos dos que os cidadãos europeus? ${ }^{52}$ Não há, em termos biológicos, qualquer justificativa que comprove que os organismos são diferentes e, por isso, se teria uma maior resistência aos efeitos nocivos.

Para ilustrar esse panorama, o inseticida Malationa é o $16^{\circ}$ agrotóxico mais vendido no Brasil e tem como LMR dezesseis vezes maior que na União Europeia, sendo permitido $8 \mathrm{mg} / \mathrm{kg}$ no Brasil, enquanto $0,5 \mathrm{mg} /$ $\mathrm{kg}$ na União Europeia ${ }^{53}$.

A falta de equidade nas políticas públicas dos países do Sul Global é algo recorrente. Na década de 80, a sociedade civil promoveu campanhas para denunciar o efeito nocivo de políticas do Banco Mundial de apoio a projetos de desenvolvimento em países de baixa renda, expondo as falhas referentes à redução da pobreza, respeito aos direitos dos povos indígenas e de proteção ambiental. Esse movimento demandou de cortes nacionais e organizações internacionais o reconhecimento da

\footnotetext{
50 Os desreguladores endócrinos são substâncias, incluindo vários pesticidas, que interferirem com os sistemas endócrinos dos seres humanos e dos animais selvagens, causando efeitos nocivos como o câncer, alterações comportamentais e anomalias reprodutivas, mesmo com uma exposição a doses extremamente baixas. (COMISSÃO DAS COMUNIDADES EUROPEIAS. Para uma estratégia temática da utilização sustentável dos pesticidas. Bruxelas: $\operatorname{Com}(2002) 349$ Final, 2002. Disponível em: http://ec.europa.eu/transparency/regdoc/rep/1/2002/PT/1-2002-349-PT-F1-1.Pdf. Acesso em: 15 jun. 2017. p.14).

51 AGROTÓXICOS e Saúde. Florianopolis: Ministeriopublicosc, 2019. 1 vídeo (0:57 seg.). Disponível em: https://www.youtube. com/watch?v=stn1CnOt_Oc. Acesso em: 25 mar. 2019.

52 Importante ressaltar que embora se tenha um cenário de injustiça ambiental, onde as populações vulneráveis consomem maior quantidade de agrotóxicos, há também o chamado 'círculo do veneno’ onde a produção agrícola dos países do Sul Global é exportada para os países do Norte contendo quantias alarmantes de agrotóxicos ou até mesmo com resíduos de agrotóxicos banidos em seus países de origem, visto que a legislação daqueles países são mais permissivas. ALBUQUERQUE, Letícia. Poluentes orgânicos persistentes: uma analise da Convenção de Estocolmo. Curitiba: Juruá, 2006.

53 BOMBARDI, Larissa Mies. Geografia do Uso de Agrotóxicos no Brasil e conexões com a União Europeia. São Paulo: Fflch - Usp, 2017. p, 254.
}

responsabilidade de empresas por violações de direitos humanos ${ }^{54}$.

Fruto das demandas de limitar práticas corporativas abusivas em busca da responsabilização de empresas nas violações de direitos humanos, consolidaram-se as Normas sobre Responsabilidades em Direitos Humanos das Empresas Transnacionais e Outras Empreendimentos Privados, cujo texto enuncia princípios no sentido de que

[...] embora os Estados sejam os principais sujeitos de deveres, agentes empresariais também possuem obrigações perante o direito internacional dos direitos humanos; estas obrigações se aplicam de maneira universal e dizem respeito a um leque amplo de direitos; governos precisam tomar medidas para proteger os indivíduos contra abusos perpetrados por empresas $[\ldots]^{55}$.

Os exemplos descritos ilustram um caminho evolutivo do direito internacional na proteção dos direitos humanos e sua relação com o meio ambiente.

Em paralelo a esses movimentos, que demandavam sanções aos atos lesivos praticados por transnacionais, iniciou-se a discussão acerca do ecocídio, que seria o reconhecimento de um crime internacional contra o meio ambiente a exemplo dos crimes contra a humanidade. Essa discussão ganhou amplitude após o lançamento pelos Estados Unidos do Agente Laranja no Vietnã ${ }^{56}$.

Nesse panorama, não se pode olvidar a importância no reconhecimento de uma jurisdição internacional penal, por meio do Tribunal Penal Internacional, criado pelo Tratado de Roma em 1998 com competência para julgar crimes contra a humanidade, crimes de guerra, crime de genocídio e crime de agressão.

Todavia, sendo os direitos humanos um processo de construção e reconstrução a partir das demandas so-

54 FEENEY, Patricia. A luta por responsabilidade das empresas no âmbito das Nações Unidas e o futuro da agenda de advocacy. Sur, Rev. int. direitos human., v.6, n.11, p.174-191, 2009. DOI: http:// dx.doi.org/10.1590/S1806-64452009000200009.

55 FEENEY, Patricia. A luta por responsabilidade das empresas no âmbito das Nações Unidas e o futuro da agenda de advocacy. Sur, Rev. int. direitos human., v.6, n.11, p.179. 2009. DOI: http://dx.doi. org/10.1590/S1806-64452009000200009.

56 BROCHADO NETO, Djalma Alvarez; ALVERNE, Tarin Cristino Frota Mont'. Ecocídio: proposta de uma política criminalizadora de delitos ambientais internacionais ou tipo penal propriamente dito? Revista Brasileira de Políticas Públicas, Brasília, v. 8, n. 1, p.211-226, 22 maio 2018. DOI: http://dx.doi.org/10.5102/rbpp.v8i1.5203. Disponível em: https://www.publicacoesacademicas.uniceub.br/ RBPP/article/view/5203/3751. Acesso em: 20 jun. 2019. 
ciais, do espaço simbólico de lutas e ação social ${ }^{57}$, no atual estágio de degradação da vida planetária, há a necessidade de se buscar um instrumento forte que possibilite eficácia na proteção ambiental.

Percebemos, assim, que, apesar dos diversos instrumentos protetivos ambientais que reafirmam compromissos assumidos nas Conferências sobre o tema, não se encontrou um mecanismo jurídico capaz de reduzir a prática de determinadas condutas nocivas, como no caso dos agrotóxicos onde danos ambientais e humanos continuam sendo cometidos, até mesmo em larga escala.

No Brasil há uma gama de legislações protetivas, porém essa proteção está sempre atrelada ao fator econômico e, por consequência, à questão transnacional. Nesse sentido, o interesse político local flexibiliza a proteção, deixando um nível protetivo ineficaz. As empresas transnacionais optam por construir suas plantas operacionais, via de regra onde se produz a poluição, em países com legislação ambiental e social mais branda.

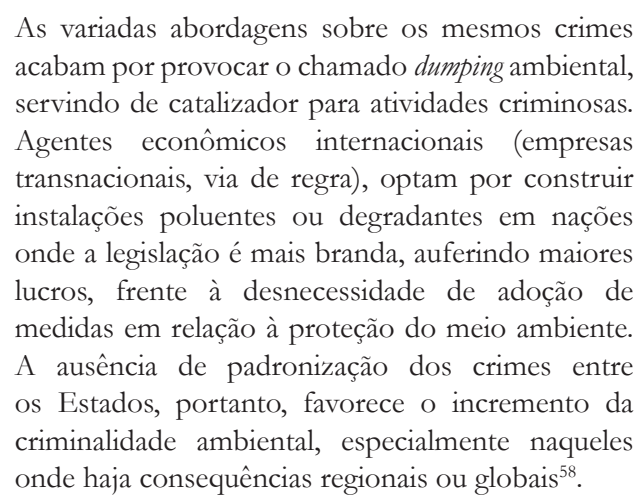

Há uma crítica, portanto, a respeito dessa falta de equidade da legislação ambiental que promove a possibilidade das corporações escolherem "o melhor país para depositar seus rejeitos e contaminação". Nesse caminho se entende importante uma padronização dos crimes cometidos contra a natureza.

Este é um dos aportes do crime de ecocídio, que apresenta diversas conotações, podendo ser entendido como um tipo penal em si, como um movimento de cri-

\footnotetext{
57 PIOVESAN, Flávia. Direitos Humanos: desafios e perspectivas contemporâneas. Rev. TST, Brasília, v. 75, n. 1, jan/mar 2009.

58 BROCHADO NETO, Djalma Alvarez; ALVERNE, Tarin Cristino Frota Mont'. Ecocídio: proposta de uma política criminalizadora de delitos ambientais internacionais ou tipo penal propriamente dito? Revista Brasileira de Políticas Públicas, Brasília, v. 8, n. 1, p.211-226, 22 maio 2018. DOI: http://dx.doi.org/10.5102/rbpp.v8i1.5203. Disponível em: https://www.publicacoesacademicas.uniceub.br/ RBPP/article/view/5203/3751. Acesso em: 20 jun. 2019.
}

minalização, como movimentos a favor de uma maior proteção do meio ambiente, como uma categoria de criminalização moral ${ }^{59}$.

[...] o ecocídio, reconhecidamente um crime grave e de grandes proporções, funciona como bandeira de uma política de proteção penal do meio ambiente. Reconhecê-lo neste último sentido significa, portanto, promover uma série de discussões legislativas e doutrinárias com definição de diversos crimes ambientais, meios de reparação e compensação dos danos, análises de responsabilidade criminal, civil e administrativa de pessoas físicas e jurídicas, reflexões sobre a existência de personalidade da natureza, entre outros temas. O ecocídio, nestes termos, não se adstringe a um tipo penal: resume uma diretriz a nortear países e Organizações Internacionais (OIs) rumo à criminalização efetiva de condutas prejudiciais à natureza e sua preservação. ${ }^{60}$

Ecocídio $^{61}$ está atrelado aos crimes ambientais de grande escala, a destruição intencional do todo ou parte de um ecossistema global, aos crimes ambientais internacionais de grande monta por meio da lesão ao direito a um meio ambiente saudável, a perda de ecossistemas de um determinado território cuja influência se perpetua na sobrevivência dos habitantes daquele território, a extinção massiva das espécies por meio das atividades antropogênicas $^{62}$.

59 DAROS, Leatrice Faraco. Justiça ecológica e crime internacional: os limites e as possibilidades do direito no combate ao ecocídio. 2018. Dissertação (Mestrado em Direito) - Centro de Ciências Jurídicas, Universidade Federal de Santa Catarina, Florianópolis, 2018. Disponível em: https://repositorio.ufsc.br/bitstream/ handle/123456789/190258/PDPC1380-D.pdf? sequence $=$ 1\&isAllowed=y. Acesso em: 20 jun. 2019.

${ }^{60}$ BROCHADO NETO, Djalma Alvarez; ALVERNE, Tarin Cristino Frota Mont'. Ecocídio: proposta de uma política criminalizadora de delitos ambientais internacionais ou tipo penal propriamente dito? Revista Brasileira de Políticas Públicas, Brasília, v. 8, n. 1, p. 220, 22 maio 2018. DOI: http://dx.doi.org/10.5102/rbpp.v8i1.5203. Disponível em: https://www.publicacoesacademicas.uniceub.br/ RBPP/article/view/5203/3751. Acesso em: 20 jun. 2019.

${ }_{61}$ Não se pretende aqui discutir se o ecocídio seria um movimento de criminalização geral de diversas condutas contra o meio ambiente ou se seria um tipo penal, o ecocídio "política pública" ou o "ecocídio crime". BROCHADO NETO, Djalma Alvarez; ALVERNE, Tarin Cristino Frota Mont'. Ecocídio: proposta de uma política criminalizadora de delitos ambientais internacionais ou tipo penal propriamente dito? Revista Brasileira de Políticas Públicas, Brasília, v. 8, n. 1, p.211-226, 22 maio 2018. DOI: http://dx.doi.org/10.5102/ rbpp.v8i1.5203. Disponível em: https://www.publicacoesacademicas.uniceub.br/RBPP/article/view/5203/3751. Acesso em: 20 jun. 2019.

62 DAROS, Leatrice Faraco. Justiça ecológica e crime internacional: os limites e as possibilidades do direito no combate ao ecocídio. 2018. Dissertação (Mestrado em Direito) - Centro de Ciências Jurídicas, Universidade Federal de Santa Catarina, Florianópo- 
Quando se analisa toda a flexibilidade da legislação protetiva perante as atividades e comércio de agrotóxicos, se conclui que não há mais uma tentativa de ocultação de efeitos nocivos, mas uma atuação conivente de envenenamento gradativo dos seres humanos, dos seres não humanos, de toda a biodiversidade que promove o equilíbrio planetário. Tanto é importante analisar essa atividade química espalhada pelo globo terrestre que um dos exemplos de ecocídio é a relação dos agrotóxicos com o extermínio de espécies de pássaros. ${ }^{63}$

Em tempos mais remotos, se poderia afirmar que os danos e os riscos ambientais eram ocultados pelas grandes corporações, todavia, atualmente não se tem mais um ocultamento da nocividade, mas sim um consentimento dado pelo governo aos interesses privados das grandes corporações na contínua degradação da vida do planeta.

Analisando as medidas de flexibilização da legislação ambiental quanto ao retrocesso na proteção da contaminação por agrotóxicos, seja pela utilização de agrotóxicos já banidos por seus comprovados efeitos nocivos, seja por uma ingestão em doses diárias permitidas, as decisões políticas têm permitido infringir danos irreversíveis e perpétuos aos seres humanos, não humanos e a natureza.

Por isso, há um ecocídio consentido, em que a vida perde o sentido frente aos interesses econômicos, e as decisões sobre políticas públicas permitem um quadro de agravamento da contaminação ambiental, com consequências para a vida e a saúde de todas as formas vivas planetárias.

\section{Considerações finais}

Diferenças de aplicação do Princípio da Precaução nos continentes europeu e americano são um fator preponderante a ensejar a adoção de regulações internacionais sobre liberação e uso de agrotóxicos que levem em conta, seriamente, o Princípio da Precaução, considerando-se, ainda, os efeitos dessas substâncias sobre os direitos humanos à saúde e alimentação adequada.

lis, 2018. Disponível em: https://repositorio.ufsc.br/bitstream/ handle/123456789/190258/PDPC1380-D.pdf ? sequence $=-$ 1\&isAllowed=y. Acesso em: 20 jun. 2019.

63 https://cop21.endecocide.org/en/examples-of-ecocide-2/
A criação de um instrumento internacional de caráter vinculativo se faz necessário para assegurar respeito e proteção aos direitos humanos à alimentação adequada e à saúde através da proibição da prática ainda recorrente de exportação de agrotóxicos banidos em seus países e continentes de origem.

Afinal de contas, analisar os agrotóxicos na perspectiva dos direitos humanos impõe reconhecer a universalidade a todas as pessoas dos direitos à alimentação adequada e à saúde, superando discriminação de povos que hoje ainda suportam, desproporcionalmente, os ônus dos agrotóxicos perigosos.

A agroecologia se apresenta como uma grande oportunidade de alternativa ao modelo do uso intensivo de agrotóxicos, capaz de alimentar toda a população mundial assegurando que ela pode ser adequadamente nutrida, por um modelo sustentável que substituiu o químico pelo biológico.

Esse modelo estimula práticas agrícolas mais adaptadas ao ambiente local e promove a fertilidade e saúde do solo a longo prazo, promove a melhora da qualidade do ar, do solo e das águas superficiais e subterrâneas permitindo a preservação dos serviços ecossistêmicos, como o controle natural de pragas, e ajudando ainda a mitigar os efeitos das mudanças climáticas reduzindo as emissões de gases de efeito estufa.

O Brasil, em vez de caminhar no sentido dos avanços científicos nacionais e internacionais relatados no relatório analisado, encontra-se sob ameaça de experimentar um grave retrocesso na proteção ao uso de agrotóxicos, que é parte de um amplo e intenso processo de retrocesso ambiental em que se encontra inserido o país.

Um desses retrocessos pretende interferir na legislação federal de autorização e registro de agrotóxicos, em sentido contrário à recomendação do relatório do Conselho de Direitos Humanos da ONU, que reforça a necessidade de cooperação entre os órgãos responsáveis da agricultura, saúde pública e meio ambiente na regulação e controle para evitar os impactos adversos dos agrotóxicos e mitigar os riscos relacionados ao seu uso indevido e intensivo. 


\section{Referências}

AGÊNCIA Nacional de Vigilância Sanitária. 2012. Disponível em: http://portal.anvisa.gov.br/resultado-de- busca?p_p_id=101\&p_p_lifecycle=0\&p_p_ state $=$ maximized $\&$ p_p_mode $=$ view \&p_p_col_ $\mathrm{id}=$ column-1\&p_p_col_count $=1 \&$ \&101_struts_ action $=\% 2$ Fasset_publisher $\% 2$ Fview_content\&_101_ assetEntryId=2665456\&_101_type=content\&_101_ groupId=219201\&_101_urlTitle=seminariovolta-a-discutir-mercado-de-agrotoxicos-em2012\&inheritRedirect $=$ true

AGROTÓXICOS e Saúde. Florianopolis: Ministeriopublicosc, 2019. 1 vídeo (0:57 seg.). Disponível em: https://www.youtube.com/watch?v=stn1CnOt_Oc. Acesso em: 25 mar. 2019.

ALBUQUERQUE, Letícia. Conflitos socioambientais na zona costeira catarinense. Tese (Doutorado em Direito) Programa de Pós-graduação em Direito, Universidade Federal de Santa Catarina. Florianópolis, 2009.

ALBUQUERQUE, Letícia. Poluentes orgânicos persistentes: uma análise da Convenção de Estocolmo. Curitiba: Juruá, 2006.

BOMBARDI, Larissa Mies. Geografia do uso de agrotóxicos no Brasil e conexões com a União Europeia. São Paulo: Fflch - Usp, 2017.

BOMBARDI, Larissa Mies. Pequeno ensaio cartográfico sobre o do uso de agrotóxicos no Brasil. São Paulo: Laboratório de Geografia Agrária - Usp, 2016.

BROCHADO NETO, Djalma Alvarez; ALVERNE, Tarin Cristino Frota Mont'. Ecocídio: proposta de uma política criminalizadora de delitos ambientais internacionais ou tipo penal propriamente dito? Revista Brasileira de Políticas Públicas, Brasília, v. 8, n. 1, p.211-226, 22 maio 2018. DOI: http://dx.doi.org/10.5102/rbpp. v8i1.5203. Disponível em: https://www.publicacoesacademicas.uniceub.br/RBPP/article/view/5203/3751. Acesso em: 20 jun. 2019.

CARNEIRO, Fernando Ferreira (org.). Dossiê ABRASCO: um alerta sobre os impactos dos agrotóxicos na saúde. Rio de Janeiro: EPSJV; São Paulo: Expressão Popular, 2015. Disponível em: http://www.abrasco.org. br/dossieagrotoxicos/wp-content/uploads/2013/10/ DossieAbrasco_2015_web.pdf. Acesso em: 10 jul. 2016. CARSON, Rachel. Silent Spring. Boston: Mariner Books,
2002.

COMISSÃO DAS COMUNIDADES EUROPEIAS. Para uma estratégia temática da utilização sustentável dos pesticidas. Bruxelas: Com(2002) 349 Final, 2002. Disponível em: http://ec.europa.eu/transparency/regdoc/ rep/1/2002/PT/1-2002-349-PT-F1-1.Pdf. Acesso em: 15 jun. 2017.

CONFERÊNCIA DAS NAÇÕES UNIDAS. Declaração de Estocolmo sobre o Ambiente Humano. Estocolmo, 1972. Disponível em: http://www.silex.com.br/leis/normas/ estocolmo.htm. Acesso em: 20 jun. 2019.

DAROS, Leatrice Faraco. Justiça ecológica e crime internacional: os limites e as possibilidades do direito no combate ao ecocídio. 2018. Dissertação (Mestrado em Direito) - Centro de Ciências Jurídicas, Universidade Federal de Santa Catarina, Florianópolis, 2018. Disponível em: https://repositorio.ufsc.br/ bitstream/handle/123456789/190258/PDPC1380-D. pdf ?sequence $=-1$ \&isAllowed $=y$. Acesso em: 20 jun. 2019.

DIÁRIO OFICIAL DA UNIÃO. Ato $n^{\circ} 24$, de 9 de abril de 2019. Brasília.

END ecocide on earth. Disponível em: https://www. endecocide.org/. Acesso em: 20 jun. 2019.

FEENEY, Patricia. A luta por responsabilidade das empresas no âmbito das Nações Unidas e o futuro da agenda de advocacy. Sur, Rev. int. direitos human., v.6, n.11, p.174-191, 2009. DOI: http://dx.doi.org/10.1590/ S1806-64452009000200009.

FREITAS, Cleuton César Ripol de. A Pulverização Aérea na Escola Rural São José do Pontal: uma abordagem dos fatos e suas circunstâncias. In: SOUSA, Murilo Mendonça Oliveira de; FOLGADO, Cleber Adriano Rodrigues (org.). Agrotóxicos: violações socioambientais e direitos humanos no Brasil. Anápolis: Universidade de Goiás, 2016.

GAUCHAZH (ed.). Liberação de agrotóxicos no Brasil é a maior em 14 anos. 2019. Disponível em: https://gauchazh.clicrbs.com.br/economia/campo-e-lavoura/ noticia/2019/06/liberacao-de-agrotoxicos-no-brasil-ea-maior-em-14-anos-cjwjs4f1203at01oi1ew0o9en.html. Acesso em: 20 jun. 2019.

GILLAM. The Guardian Carey (ed.). Who is paying for Monsanto's crimes? We are. 2019. Disponível em: https:/ / www.theguardian.com/commentisfree/2019/mar/30/ 
who-is-paying-for-monsantos-crimes-we-are. Acesso em: 20 jun. 2019.

JENDROSKA, Jerzy; BAR, Magdalena. Procedural Enviromental Rights: Principle X In Thepry and Practice. Cambridge: Intersentia Ltd, 2017.

LE PRESTRE, Philippe. Ecopolitica Internacional. São Paulo: Senac, 2000.

LIMA, Juliana Schmitz Paes de. Interdependência e os organismos internacionais. In: OLIVEIRA, Odete Maria de; RI JÚNIOR, Arno dal (org.). Relações Internacionais: interdependência e sociedade global. Ijuí: Unijuí, 2003.

NYE, Joseph S. Soft power: the means to sucess in world politics. New York: Public Affairs, 2016.

ONU BRASIL. Relator e chefe ambiental da onu cobram reconhecimento do direito bumano a um planeta saudavel. Disponível em: https://nacoesunidas.org/relator-e-chefeambiental-da-onu-cobram-reconhecimento-do-direitohumano-a-um-planeta-saudavel/. Acesso em: 5 jun. 2018.

ORGANIZAÇAO DAS NAÇOES UNIDAS. Agenda 2030. Disponível em: https://nacoesunidas.org/ pos2015/agenda2030/. Acesso em: 20 jun. 2019.

ORGANIZAÇÃO PAN-AMERICANA DA SAÚDE; ORGANIZAÇÃO MUNDIAL DA SAÚDE. OPAS/ OMS destaca importância da atuação conjunta de setores da saúde, agricultura e meio ambiente na regulamentação de agrotóxicos. 2018. Disponível em: https://www.paho.org/bra/ index.php?option $=$ com_content\&view $=$ article\&id $=57$ 56:opas-oms-destaca-importancia-da-atuacao-conjunta-dos-setores-da-saude-agricultura-e-meio-ambientena-regulamentacao-de-agrotoxicos\&Itemid $=839$. Acesso em : 21 de junho de 2019.

ORTIZ, Eduardo. El estúdio de las relaciones internacionales. Santiago do Chile: Fondo de Cultura Economica, 2004.
PIOVESAN, Flávia. Direitos Humanos: desafios e perspectivas contemporâneas. Rev. TST, Brasília, v. 75, n. 1, jan/mar 2009.

PRIEUR, Michel. O Princípio da Proibição de Retrocesso Ambiental. In: SENADO FEDERAL (org.). O Princípio da proibição de retrocesso ambiental. Brasília: Senado Federal, 2012. Disponível em: http:/ /www2.senado.leg. br/bdsf/handle/id/242559. Acesso em: 20 jun. 2019.

REUTERS. Ministério da Agricultura aprova registro de mais 42 agrotóxicos, totalizando 211 no ano. 2019. Disponível em: https://g1.globo.com/economia/agronegocios/ noticia/2019/06/24/ministerio-da-agricultura-aprovaregistro-de-mais-42-agrotoxicos-totalizando-211-noano.ghtml. Acesso em: 20 jun. 2019.

UN ENVIRONMENT PROGRAMME. About UN environment. Disponível em: https://www.unenvironment. org/pt-br/node/705. Acesso em: 25 jun. 2019.

UNITED NATIONS. General Assembly. A/ HRC/34/48. Human Rights Council. Report of the Special Rapporteur on the right to food. Disponível em: http://ap.ohchr.org/documents/dpage_e.aspx?si=A/ HRC/34/48. Acesso em: 21 jun. 2019.

UNITED NATIONS. General Assembly. A/ RES/66/288. Disponível em: https://undocs.org/ en/A/66/PV.123. Acesso em: 25 jun. 2019.

VOIGT, Christina. Integration and ecological integrity. In: Christina Voigt (ed.). Rule of law for nature: new dimensions and ideas in environmental law. Cambridge: Cambridge University Press, 2013.

WODAGENEH, Alemayehu. Trouble in Store. 1997. Disponível em: http://www.ourplanet.com/imgversn/86/woda.html. Acesso em: 25 ago. 2016. 
Para publicar na Revista de Direito Internacional, acesse o endereço eletrônico www.rdi.uniceub.br ou www.brazilianjournal.org.

Observe as normas de publicação, para facilitar e agilizar o trabalho de edição. 